\title{
Advantages of Screening for Glucose Tolerance in the Sequential Weeks of Gestation
}

\author{
Veeraswamy Seshiah ${ }^{1}$ Vijayam Balaji ${ }^{1}$ Anjalakshi Chandrasekar ${ }^{2}$ Ashok Kumar Das ${ }^{3}$ \\ Samar Banerjee $^{4}$ A. Paneerselvam ${ }^{5} \quad$ Rajesh Jain $^{6} \quad$ N. Bhavatharani ${ }^{7}$
}

${ }^{1}$ Dr. V. Balaji Diabetes Care Center and Dr. V. Seshiah Research Institute, Chennai, Tamil Nadu, India

${ }^{2}$ Madha Medical College, Kancheepuram, Tamil Nadu, India

3 Pondicherry Institute of Medical Science, Pondicherry, India

${ }^{4}$ Vivekananda Institute of Medical Science, Kolkata, India

${ }^{5}$ Aruna Diabetes Centre, Chennai, Tamil Nadu, India

6 Jain Hospital, Kanpur, Uttar Pradesh, India

${ }^{7}$ SRC Diabetes Centre, Erode, Tamil Nadu, India

\begin{abstract}
Address for correspondence Veeraswamy Seshiah, MD, FRCP, Dr. V. Balaji Diabetes Care Center and Dr. V. Seshiah Research Institute, \#729, Poonamallee High Rd, Aminjikarai, Chennai, Tamil Nadu, 600030, India (e-mail:vseshiah@gmail.com).
\end{abstract}

J Soc Health Diab 2021;9:e1-e7.

\begin{abstract}
Keywords

- gestational diabetes mellitus

- glucose tolerance

- screening

Prelife exposure relates to development during the time preceding the first appearance of life, a time course from "conception to confinement." From single cell zygote to finally formed fetus at confinement, a remarkable change occurs due to maternal fuels and hormonal influence on the fetal development. The crucial period in the fetal development is the first trimester. Early exposure to aberrant maternal metabolism in the embryonic developmental stage would result in congenital malformation and fetal wastage. Maintaining maternal glucose at the recommended level of fasting 80 to $90 \mathrm{mg}$ and 2 hours postprandial plasma glucose 110 to $120 \mathrm{mg} / \mathrm{dL}$ during preconceptional period and throughout pregnancy is the assurance for the healthy offspring with ideal birth weight of 2.5 to $3.5 \mathrm{~kg}$ and prevention of noncommunicable diseases in the future.
\end{abstract}

\section{Introduction}

David Barker's "Fetal Origin of Adult Diseases Theory" conceptualized that the body's susceptibility to "lifestyle" diseases was programmed in the intrauterine period. Intrauterine programming is a process whereby stimuli or stresses occurring at critical or sensitive periods of fetal development permanently change structure, physiology, and metabolism, thereby predisposing individuals to disease in adult life. ${ }^{2}$ If the stimulus happens to be hyperglycemia in pregnancy, the consequent abnormal maternal metabolic environment affects the developing fetal tissues, organs, and control systems in complex ways that eventually lead to permanent functional changes in adult life. The quantum of hyperglycemic exposure in terms of duration and degree is relevant, as is the timing of the onset of exposure in the course of pregnancy. Early exposure during fetal organogenesis and placental development has relatively more severe and lasting consequences than later exposure. ${ }^{3}$ Depending on the timing and quantum of exposure to the aberrant fuel mixture, different effects may occur on the embryo-fetus including abortion, congenital anomalies, macrosomia, and large for gestational age, intrauterine growth restriction (IUGR) and small for gestational age, intrauterine death and still births, etc. ${ }^{4}$ (-Table $\left.\mathbf{1}\right)$.

\section{Short-Term Hyperglycemia Complications in the Mother}

- Increased infections

- Pregnancy-induced hypertension
DOI https://doi.org/ $10.1055 / \mathrm{s}-0041-1736086$ ISSN 2321-0656
(C) 2021. Novo Nordisk Education Foundation.

This is an open access article published by Thieme under the terms of the Creative Commons Attribution-NonDerivative-NonCommercial-License, permitting copying and reproduction so long as the original work is given appropriate credit. Contents may not be used for commercial purposes, or adapted, remixed, transformed or built upon. (https://creativecommons.org/licenses/by-nc-nd/4.0/).

Thieme Medical and Scientific Publishers Pvt. Ltd. A-12, 2nd Floor, Sector 2, Noida-201301 UP, India 
Table 1 Short-term complications in the offspring due to hyperglycemia

\begin{tabular}{|c|c|c|c|}
\hline First trimester & Second trimester & Third trimester & Postpartum and neonatal \\
\hline $\begin{array}{l}\text { First } 6 \text { weeks postovulation-increased } \\
\text { anomalies-diabetic embryopathy } \\
\text { 3rd week-caudal regression syndrome } \\
\text { 4th week-Spina bifida and } \\
\text { anencephaly } \\
\text { 5th week-Transposition of great ves- } \\
\text { sels, renal anomalies } \\
\text { 6th week-Ventricular septal defects, } \\
\text { anal atresia, increased fetal wastage }\end{array}$ & $\begin{array}{l}\text { Diabetic fetopathy } \\
\text { Behavioral abnormalities } \\
\text { Skeletal abnormali- } \\
\text { ties-femoral hypoplasia } \\
\text { Unusual facial phenotype } \\
\text { Macrosomia }\end{array}$ & $\begin{array}{l}\text { Diabetic fetopathy- } \\
\text { Preterm labor, PROM, } \\
\text { macrosomia, IUGR, } \\
\text { IUFD, sudden intra- } \\
\text { partum death }\end{array}$ & $\begin{array}{l}\text { Diabetic fetopathy-Sudden intrapartum } \\
\text { death, shoulder dystocia, birth injuries } \\
\text { Increased perinatal mortality, respiratory } \\
\text { distress syndrome, hypoglycemia, hyper- } \\
\text { bilirubinemia, neonatal convulsions }\end{array}$ \\
\hline
\end{tabular}

- Hydramnios

- Macrovascular complications

- Instrumental deliveries

- Operative deliveries

- Obstetric palsies

- Puerperal sepsis.

\section{Long-Term Complications in the Mother ${ }^{5}$}

- Women with gestational diabetes mellitus (GDM) have a high vulnerability for future type 2 DM, and GDM is considered the most reliable marker for it

- Cardiometabolic disorders in women.

\section{Long-Term Complications in the Offspring ${ }^{6}$}

- Increased risk of early onset type 2 DM and obesity. Differences exist in the offspring; the risk of diabetes and obesity is based on time and type of diabetes exposure in utero.

- A negative correlation has also been shown between the severity of maternal hyperglycemia and the offspring performance on various neurodevelopmental and behavioral tests.

- Compared with children unexposed to diabetes in utero, children exposed to diabetes have been reported to be at higher risk of attention-deficit hyperactivity disorders

- Autism spectrum disorders.

- Intellectual disabilities.

- Amo remarked effect has been reported with combined exposure to maternal prepregnancy obesity and diabetes.

These effects have a proven possibility for prevention or delaying onset through appropriate postpartum lifestyle interventions.

\section{Time Course of Fetal Development from Conception to Confinement $^{7}$}

At the time of ovulation, after copulation, sperm travels through the cervix and uterus and into the fallopian tubes. Conception usually takes place in the outer third of the fallopian tube. A single sperm penetrates the egg and a fusion of the genetic information occurs. This resulting in a single cell

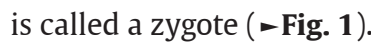

The zygote spends the next few days traveling down the fallopian tube and rapidly multiplying into number of cells

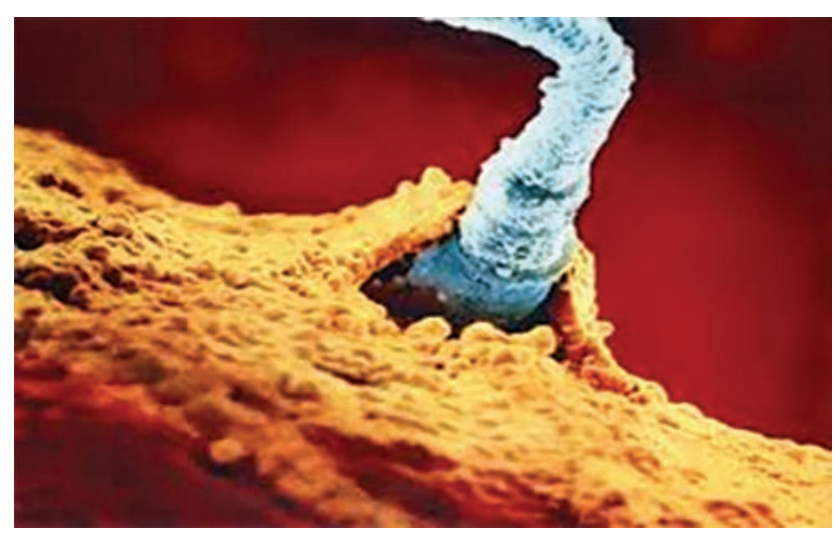

Fig. 1 Sperm entering egg. (Adopted from Prenatal Development by Dr. C. George Boeree.)

through division. A mulberry-like mass, $0.0254 \mathrm{~cm}$ wide, develops after the cell division. This ball of cells in the fallopian tube is called morula.

With additional cell division, the morula becomes a blastocyst, with an inner core and an outer shell of cells. The outer group of cells becomes the membranes that nourish and protect the inner group of cells, which becomes the fetus.

The blastocyst is implants in the uterus between the 7th and 9th day after conception. At this point, the endometrium (the lining of the uterus) has grown and is ready to support a fetus. The blastocyst burrows into the endometrium where it receives nourishment. It is barely visible, but doubles every 24 hours. The placenta and supporting infrastructure for pregnancy develop at this time as well. It is estimated that up to $55 \%$ of zygotes never reach this phase of growth.

\section{The Embryo}

The embryonic stage begins on the 15th day after conception and continues until about the 8th week, or until the embryo is $3 \mathrm{~cm}$ in length. During this period, the cells of the embryo are not only multiplying but also taking on specific functions. This process is called tissue differentiation. It is during this critical period of differentiation (most of the first trimester) that the growing fetus is most susceptible for damage from external sources (teratogens) including viral infections such as rubella radiation and (malnutrition) abnormal metabolites.

An embryo who has one developmental problem may have other problems that arose at the same time: Kidney problems and hearing defect, for example, are often found 


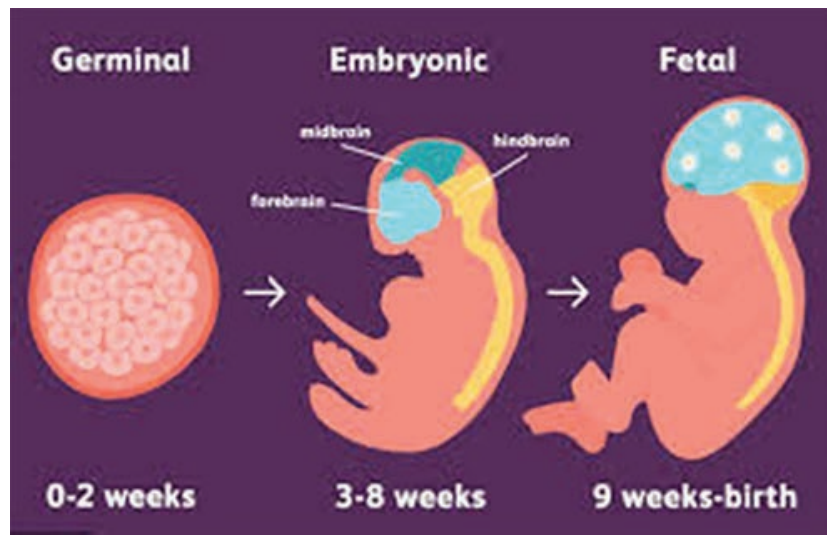

Fig. 2 Neural development. (Adopted from Development Psychology by Dr. Kendra Cherry.)

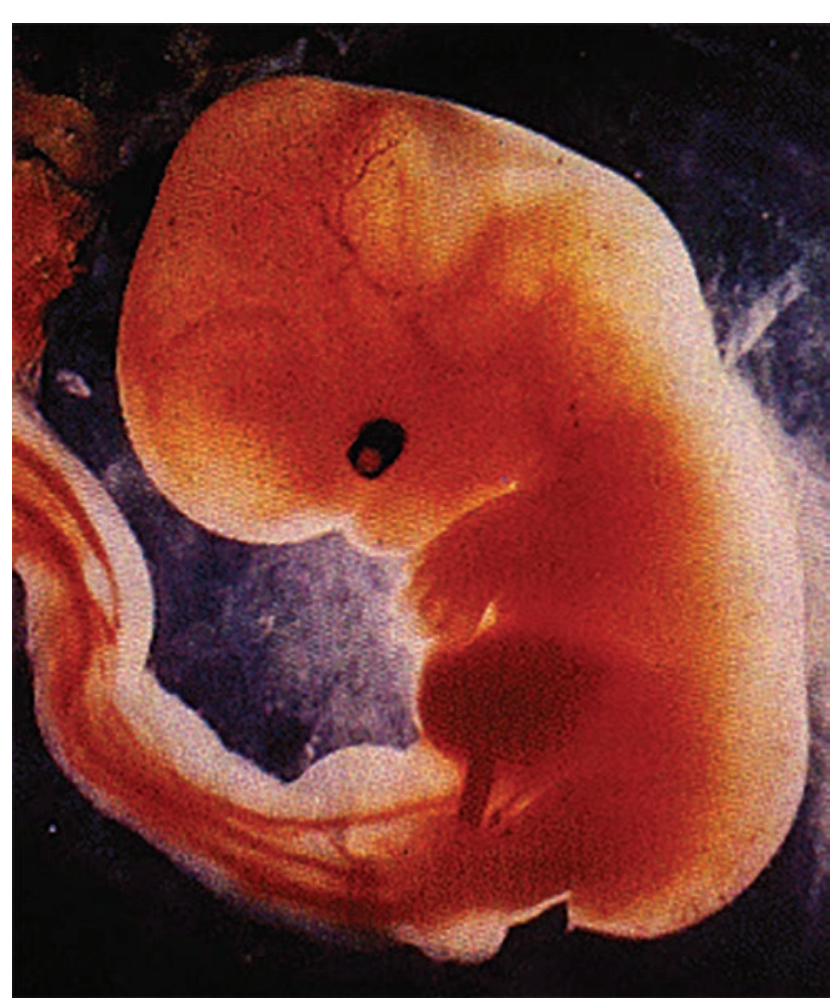

Fig. 3 Eye and ear development. (Adopted from Healthy Lifestyle, Pregnancy Week by Week by Mayo Clinic Staff.)

together because both kidneys and the inner ears develop at the same time.

Week 3-The formation of the heart, the beginning of development of the brain and spinal cord, and the beginning of the gastrointestinal tract take place (-Fig. 2).

Between 18 and 19 days after fertilization, the heart begins to form. This early development is critical for subsequent embryonic and prenatal development. The heart is the first functional organ to develop and starts to beat and pump blood at day 21 or 22 .

Teratogens introduced in this period may cause several problems such as the absence of one or more limbs or a heart that is outside of the chest cavity at birth.
Weeks 4 and 5-The embryo is $6 \mathrm{~mm}$ long: The formation of the vertebra, the lower jaw, the larynx, and the rudiments of the ear and eye begins. The heart, which is still outside body, now beats at a regular rhythm. The arm and leg "buds" are visible with hand and foot "pads" ( - Fig. 3 ).

Teratogens may cause very serious problems involving the esophagus, vertebrae, and eyes. The infant could be born with severe facial clefts or missing hands or feet.

Week $6(12.7 \mathrm{~mm}, 28.3 \mathrm{mg})$-In week 6 , the formation of the nose, jaw, palate, and lung buds occurs. The fingers and toes form, but may still be webbed. The tail is receding, and the heart is almost fully developed.

Teratogens at this point may leave the fetus with profound heart problems or a cleft lip.

Week 7 (22.2 mm, 93.5mg)-In week 7, the eyes move forward on the face, and the eyelids and tongue begin to form. All essential organs begin to form (Fig. 4).

Teratogens may cause heart and lung problems, a cleft palate, and ambiguous genitalia (not quite clear male or female).

Week $8(25.4 \mathrm{~mm}, 1.8 \mathrm{~g})$-The embryo now resembles a human being. The facial features continue to develop and the external ear and the external genitalia appear. By now, the circulation through the umbilical cord is well developed. The long bones begin to form and the muscles are able to contract.

Teratogens may still cause heart problems and stunting of the fingers and toes.

\section{The Fetus}

At this point, the embryo is developed enough to call a fetus. All organs and structures found in a full-term newborn are present.

Weeks 9 to $12(76.2 \mathrm{~mm}, 28.35 \mathrm{~g})$-The head comprises nearly half of the fetus size and the face is well formed. The eyelids close now and will not reopen until about the 28th week. The tooth buds appear. The genitalia are now clearly visible which indicate the fetus is male or female.

Weeks 13 to $16(15.2 \mathrm{~cm})$-These weeks mark the beginning of the second trimester. Although the skin of the fetus is almost transparent, fine hair develops on the head called lanugo. The fetus makes active movements, including sucking, which leads to some swallowing of the amniotic fluid. A thin dark substance called meconium is made in the intestinal tract. The heart beats 120 to 150 times per minute and brain waves are detectable.

Weeks 17 to 20 (20.3 cm, 500 g)-Eyebrows and lashes appear and nails appear on fingers and toes. This is an exciting time for the parents: The mother can feel the fetus moving ("quickening") and the fetal heartbeat can be heard with a stethoscope.

Weeks 21 to $24(28.4 \mathrm{~cm}, 766 \mathrm{~g})$-All the eye components are developed, footprints and fingerprints are formed, and the entire body is covered in cream-cheese-like vernix caseosa. The fetus now has a startle reflex.

Weeks 25 to $28(37.5 \mathrm{~cm}, 1.2 \mathrm{~kg})-$ This period is the third trimester. During these weeks, rapid brain development occurs. The nervous system is developed enough to control some body functions, and the eyelids open and close. A baby 


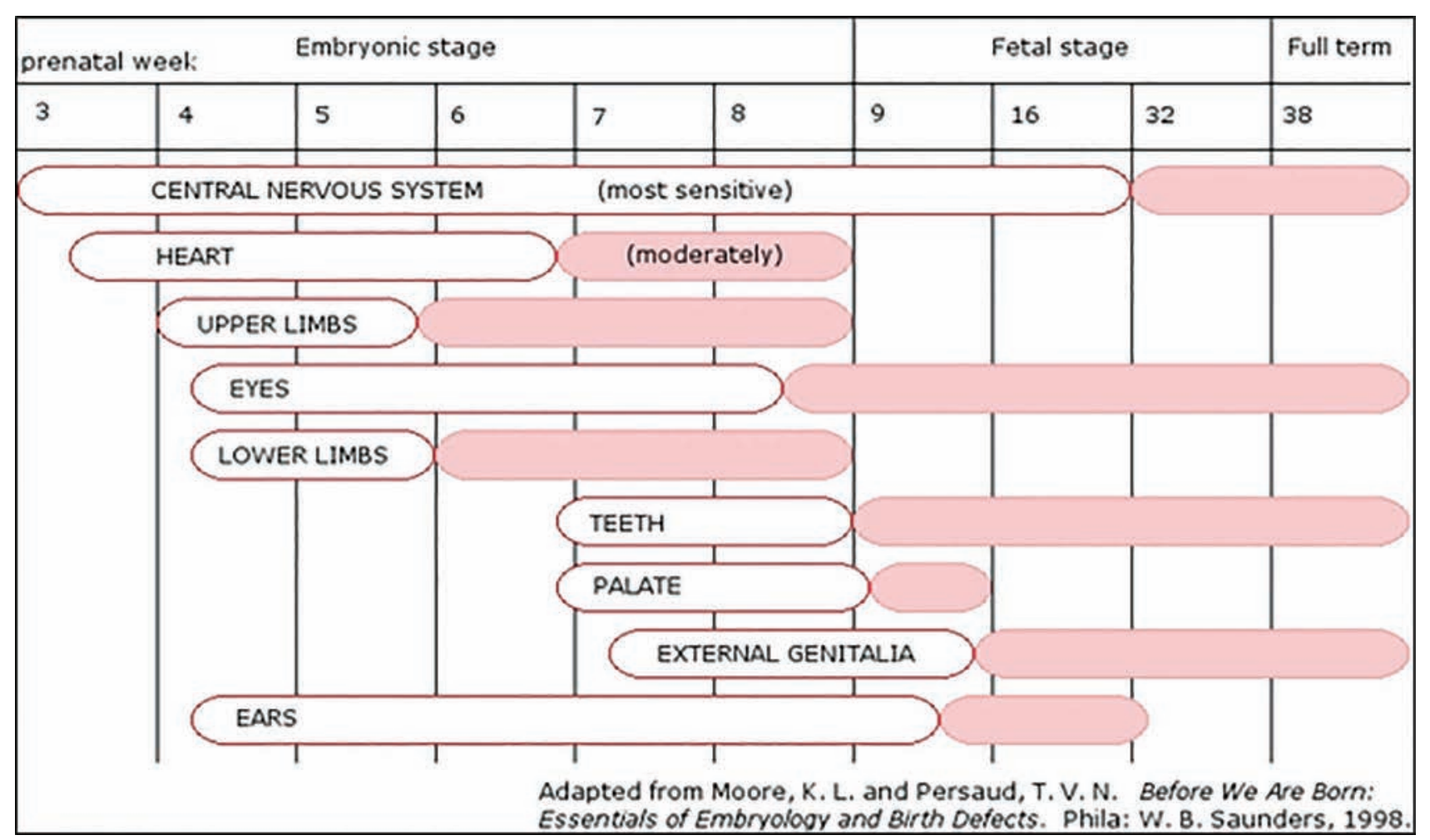

Fig. 4 Timing of birth defects.

born at this time may survive, but the chances of complications and death are high.

Weeks 29 to $32(37.5 \mathrm{~cm}-43.1 \mathrm{~cm}, 1.9 \mathrm{~kg})$-These weeks see further development toward independent life: There is a rapid increase in the amount of body fat and the fetus begins storing its own iron, calcium, and phosphorus. The bones are fully developed, but still soft and pliable. There are rhythmic breathing movements present, the fetal body temperature is partially self-controlled, and there is increased central nervous system control over body functions.

Weeks 33 to 36 (40.6-48.2 cm, 2.6-3.1 kg)-The lanugo (body hair) begins to disappear. A baby born at 36 weeks has a high chance of survival.

Weeks 37 to 40 (48.2-53.3 cm, 3.1-3.6 kg)-At 38 weeks, the fetus is considered full term. It fills the entire uterus, and its head is the same size around as its shoulders. The mother supplies the fetus with the antibodies it needs to protect it against disease.

\section{Pre- and Periconceptional Period}

Euglycemia is critical during the fertilization. During in vitro development, oocytes and zygotes cultured briefly in the absence of glucose are unable to complete embryo compactions, failing to progress beyond the morula stage. ${ }^{8}$ Hyperglycemia culture conditions are also toxic to embryos, indicating that normal development requires a narrow glucose concentration range. ${ }^{4,9}$ The ideal glycemic levels during preconceptional period and pregnancy are fasting blood glucose of $3.9 \pm 0.4 \mathrm{mmol} / \mathrm{L}(71 \pm 8 \mathrm{mg} / \mathrm{dL})$, 1 -hour postprandial glucose of $6.0 \pm 0.72 \mathrm{mmol} / \mathrm{L}(109 \pm 13 \mathrm{mg} / \mathrm{dL})$, 2-hour postprandial glucose of $5.5 \pm 0.55 \mathrm{mmol} / \mathrm{L}(99 \pm 10 \mathrm{mg} / \mathrm{dL})$, and 24 hours mean of $4.9 \pm 0.55 \mathrm{mmol} / \mathrm{L}(88 \pm 10 \mathrm{mg} / \mathrm{dL}) .{ }^{10}$

\section{Factors Operating in Organ Development and Fetal Growth}

The ovum is well supplied with mitochondria, but the sperm contains a few and even those few do not persist in the offspring. At fertilization, it is only the nucleus of the spermatozoa that enters the ovum and thus all the cytoplasm, mitochondria, and mitochondrial DNA are exclusively maternally inherited. ${ }^{11}$ Maternal inheritance is attributed to mutation in the gene(s) present on mitochondrial $(\mathrm{mt})$ DNA and is transmitted invariably by an affected mother to her progeny. The unique feature of mitochondrial $(\mathrm{mt})$ DNA is its maternal inheritance. $^{11}$

\section{Maternal Hyperglycemia and Progeny}

Exposure to a diabetic environment in utero is associated with increased occurrence of impaired glucose tolerance and a defective insulin secretary response in adult offsprings, independent of genetic predisposition to type 2 diabetes. ${ }^{12}$ This fact is established in Pima Indians. The offsprings of Pima Indians who were in utero when their mother had diabetes have a greater risk of diabetes than earlier siblings born before the mother developed diabetes. ${ }^{13}$ "Intrauterine millieu> Inherited Destiny." 


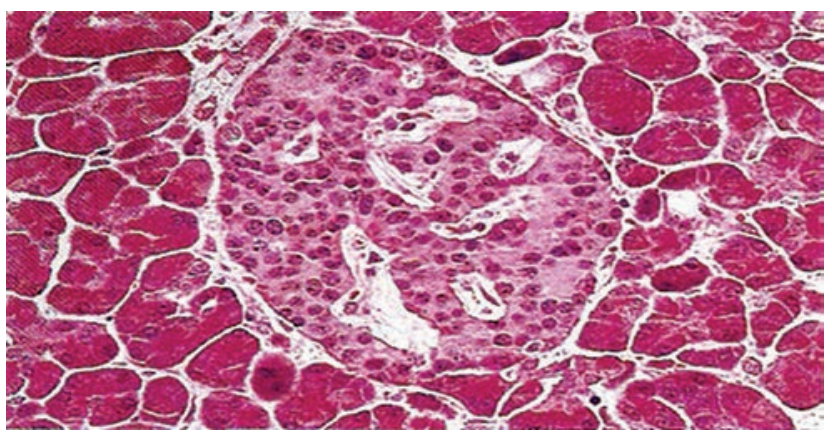

Fig. 5 Islet cells development. (Adopted from Pancreas Histology, Endocrine, Pancreas Development.)

\section{Maternal Diabetes and Fetal Insulin Secretion}

Fetal pancreas: Each islet cell functions as an endocrine organ. It appears at 11 th ( - Fig. 5) week of gestation, recognizes and responds to maternal glycemia at 15 to 16 weeks of gestation. ${ }^{14}$ Human studies have shown an increase in pancreatic $\beta$-cell mass and insulin secretion in the fetuses of poorly controlled diabetic women by 16 weeks gestation. ${ }^{15}$

\section{Influence of Maternal Hyperglycemia on Fetal Growth}

Early maternal metabolic imprinting may affect fetal growth. The priming of the $\beta$-cell mass in mid-gestation may account for the persistence of fetal hyperinsulinemia throughout pregnancy and the risk of accelerated fetal growth even when mother enjoys good metabolic control in later pregnancy. Early maternal metabolic imprinting may affect fetal growth. ${ }^{16,17}$

\section{Importance of First Trimester}

The first trimester begins on the first day of the last period and lasts until the end of week 12 . This means that by the time one knows for sure of her pregnancy, she might already be 5 or 6 weeks of pregnancy. A lot happens during the first 3 months.

Early gestation exposure to excess maternal fuels may impact the placental transport in a time dependent manner. This results in different growth pattern emphasizing that "earlier intervention" may be important. ${ }^{3}$ Though the fetal development is discussed in days and weeks, it is wiser to test the maternal glucose level on the next day woman misses her period. Very early diagnosis of pregnancy can be made by estimating serum $\beta$-hydroxy chorionic gonadotropin ( $\beta$-HCG) at the end of 3rd week of menstrual cycle and by urine $\beta$-HCG by the end of 4 th week of menstrual cycle.

\section{Rational for Early Weeks Screening}

Metabolic perturbations are underway before the usual diagnosis (24th-28th week) and that earlier screening and intervention may be warranted. ${ }^{18}$ Maegawa et al observed (63.6\%) in the first trimester and the rest (36.4\%) in the second and third trimesters. This finding suggests the importance of screening for glucose intolerance in the first trimester. ${ }^{19}$ Seshiah et al also documented that GDM manifests in all trimesters of pregnancy. ${ }^{20}$ Hence, the present concept is that there is a "Need for testing glucose tolerance in the early weeks of pregnancy."21 The diagnostic procedure recommended by Diabetes in Pregnancy Study Group India is "A Single Test Procedure."22 This procedure is approved by the Ministry of Health and Family Welfare Government of India ${ }^{23}$ and is also recognized by World Health Organization (WHO), ${ }^{24}$ International Federation of Gynecology and Obstetrics (FIGO), ${ }^{25}$ and International Diabetes Federation (IDF). ${ }^{26}$

\section{Advantages of Early Testing}

Early testing for glucose intolerance and care could avoid some diabetes-related complications such as hydramnios, fetal anomalies, macrosomia, and preterm births in women with gestational diabetes mellitus. ${ }^{20,27}$

Studies have shown glucose levels at weeks 10 to 14 were positively associated with estimated fetal weight starting at week 23 and the association becomes significant at week 27 . Higher glucose concentration in early pregnancy was significantly related to a larger fetal size in late pregnancy. ${ }^{28}$

\section{Maternal Nutrition and Target for Glycemic Control}

The goal of nutrition in pregnancy is to support maternal, placental, and fetal metabolic needs, and it may be the first introduction to a lifetime of healthy eating. ${ }^{29}$ Postprandial hyperglycemia plays a more important role in causing fetal overgrowth. Data suggests that postprandial glucose levels more closely relate to macrosomia risk compared with fasting glucose levels. ${ }^{30,31}$ Based on studies in preterm births, renal threshold for glucose in the fetus is probably $<110 \mathrm{mg} / \mathrm{dL}$.

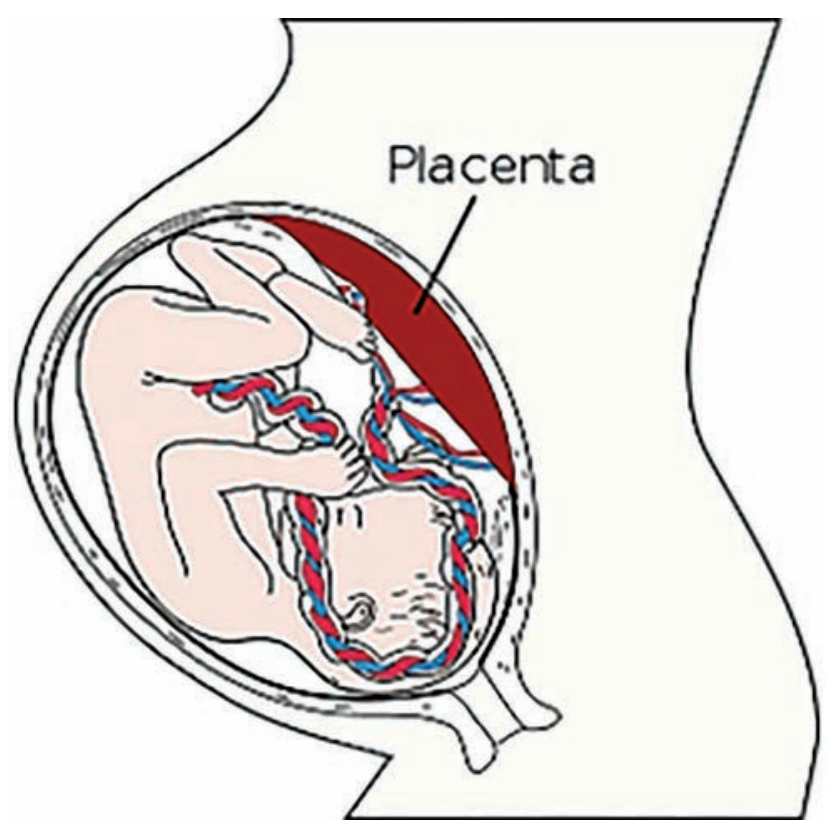

Fig. 6 Placentae. (Adopted from Wikipedia, The Free Encyclopaedia.) 


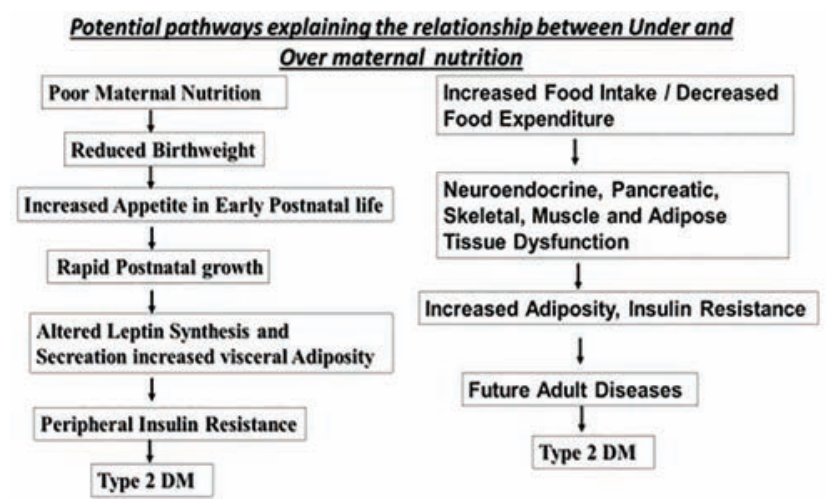

Fig. 7 Effect of maternal nutrition on offspring.

When maternal glucose level is $>110 \mathrm{mg} / \mathrm{dL}$, the fetal blood glucose load causes fetal glycosuria and consequently a glucose-enriched amniotic fluid. After 20 weeks of gestation, the fetus begins to swallow the amniotic fluid. In addition to the placental transfer of glucose, ingested high glucose amniotic fluid also stimulates insulin secretion. Thus, even transient elevations of blood glucose on the maternal side not only result in elevations of blood glucose on the fetal side but also provide for glucose ingestion by the fetus for many hours. Thus, postprandial hyperglycemia for less than 1 hour once a day in the mother may produce fetal insulin stimulus, through the oral route for hours. Elevations of maternal glucose levels more frequently (after every meal, for example) may produce a more prolonged oral glucose load for the fetus resulting in an overfed fat fetus. ${ }^{32}$ Monitoring maternal glycemia and maintaining 2 hours postprandial plasma glucose between 110 to $120 \mathrm{mg} / \mathrm{dL}$ by using plasma calibrated glucometer level every week may be a wise decision.

\section{Placenta: A Temporary Endocrine Organ}

Placenta connects the developing fetus via the umbilical cord to the uterine wall to allow nutrient uptake, thermoregulation, waste elimination, and gas exchange via the mother's blood supply to fight against internal infection and to produce hormones (hyperglycemic-antiinsulin) that support pregnancy. ${ }^{33}$ Nutrients pass through it but insulin does not cross and maternal insulin is being destroyed by placental insulinase (-Fig. 6).

\section{Maternal Nutritional Status and Its Influence on the Offspring}

The intrauterine milieu is a strong modulator of changes in the pancreatic development and peripheral insulin response. This ultimately culminates in adult onset GDM and T2 diabetes mellitus. Absolute nutritional deviations from the optimum, whether over- or undernutrition, produce the same effect on the offspring ${ }^{34}$ ( $\boldsymbol{- \text { Fig. }}$ 7). There is a great variability in fetal growth in the human, based on both genetics and environmental factors. Although we cannot control our genes (with the possible exception of epigenetic phenomena), we may be able to affect fetal growth through alteration in the maternal environment. ${ }^{35}$

\section{Conclusion}

Fetal development invariably involves exquisite interplay between maternal physiology, metabolism, and hormones. Nature nurtures the embryogenesis from conception to confinement. The environment that the oocyte is exposed to during the periconception period can have a significant impact on oocyte developmental competence (the ability of the oocyte to support fertilization and subsequent embryo development) and the long-term health of the resulting offspring. It is necessary to optimize metabolic control early in pregnancy. This will necessitate prepregnancy planning for women with preexisting diabetes, as well as for those at increased risk of GDM, and better means to safely normalize glycemia. Though the fetal development is discussed in days and weeks, it is wiser to test the maternal glucose in the periconceptional period. Monitoring maternal glycemic level every week may be cumbersome but prudent.

\section{Conflict of Interest}

None declared.

\section{References}

1 Barker DJ. The developmental origins of adult disease. J Am Coll Nutr 2004;23(6(Suppl):588S-595S

2 Lucas A. Programming by early nutrition in man. In: Bock GR, Whelan J, editors. The childhood environment and adult disease. Chichester: John Wiley \& Sons;1991. p. 38-55

3 Carpenter MW, Canick JA, Hogan JW, Shellum C, Somers M, Star JA. Amniotic fluid insulin at 14-20 weeks' gestation: association with later maternal glucose intolerance and birth macrosomia. Diabetes Care 2001;24(7):1259-1263

4 Brown HM, Green ES, Tan TCY, et al. Periconception onset diabetes is associated with embryopathy and fetal growth retardation, reproductive tract hyperglycosylation and impaired immune adaptation to pregnancy. Sci Rep 2018;8(1):2114

5 Sudasinghe $\mathrm{BH}$, Wijeyaratne $\mathrm{CN}$, Ginige PS. Long and short-term outcomes of Gestational Diabetes Mellitus (GDM) among South Asian women - a community-based study. Diabetes Res Clin Pract 2018;145:93-101

6 Damm P, Houshmand-Oeregaard A, Kelstrup L, Lauenborg J, Mathiesen ER, Clausen TD. Gestational diabetes mellitus and long-term consequences for mother and offspring: a view from Denmark. Diabetologia 2016;59(7):1396-1399

7 The Medical Encyclopaedia. U.S. National Library of Medicine. Available online at http:/www.nlm.nih.gov/medlineplus/ ency/article/002398.htm. Accessed June 28, 2021

8 Pantaleon M, Tan HY, Kafer GR, Kaye PL. Toxic effects of hyperglycemia are mediated by the hexosamine signaling pathway and o-linked glycosylation in early mouse embryos. Biol Reprod 2010;82(4):751-758

9 Frank LA, Sutton-McDowall ML, Gilchrist RB, Thompson JG. The effect of peri-conception hyperglycaemia and the involvement of the hexosamine biosynthesis pathway in mediating oocyte and embryo developmental competence. Mol Reprod Dev 2014;81(5):391-408

10 Hernandez TL, Friedman JE, Van Pelt RE, Barbour LA. Patterns of glycemia in normal pregnancy: should the current therapeutic targets be challenged? Diabetes Care 2011;34(7):1660-1668

11 Khan N, et al. Early age at onset and high frequency of associated complications in maternally transmitted type 2 diabetes mellitus. Int J Diabetes Dev Ctries 2004;24:36-39 
12 Damm P. Future risk of diabetes in mother and child after gestational diabetes mellitus. Int $\mathrm{J}$ Gynaecol Obstet 2009;104(Suppl 1):S25-S26

13 Dabelea D, Hanson RL, Bennett PH, Roumain J, Knowler WC, Pettitt DJ. Increasing prevalence of type II diabetes in American Indian children. Diabetologia 1998;41(8):904-910

14 Adam PA, Teramo K, Raiha N, Gitlin D, Schwartz R. Human fetal insulin metabolism early in gestation. Response to acute elevation of the fetal glucose concentration and placental transfer of human insulin-I-131. Diabetes 1969;18(6):409-416

15 Reiher H, Fuhrmann K, Noack S, et al. Age-dependent insulin secretion of the endocrine pancreas in vitro from fetuses of diabetic and nondiabetic patients. Diabetes Care 1983;6(5):446-451

16 Desoye G, Nolan CJ. The fetal glucose steal: an underappreciated phenomenon in diabetic pregnancy. Diabetologia 2016;59(6):1089-1094

17 Schwartz R, Gruppuso PA, Petzold K, Brambilla D, Hiilesmaa V, Teramo KA. Hyperinsulinemia and macrosomia in the fetus of the diabetic mother. Diabetes Care 1994;17(7):640-648

18 Tisi DK, Burns DH, Luskey GW, Koski KG. Fetal exposure to altered amniotic fluid glucose, insulin, and insulin-like growth factor-binding protein 1 occurs before screening for gestational diabetes mellitus. Diabetes Care 2011;34(1):139-144

19 Maegawa Y, Sugiyama T, Kusaka H, Mitao M, Toyoda N. Screening tests for gestational diabetes in Japan in the 1st and 2nd trimester of pregnancy. Diabetes Res Clin Pract 2003;62(1):47-53

20 Seshiah V, Balaji V, Balajiet MS, et al. GDM manifests in all trimesters of pregnancy. Diabetes Res Clin Pract 2007;77(3):482-484

21 Veeraswamy S, Divakar H, Gupte S, Datta M, Kapur A, Vijayam B. Need for testing glucose tolerance in the early weeks of pregnancy. Indian J Endocrinol Metab 2016;20(1):43-46

22 Anjalakshi C, Balaji V, Balaji MS, et al. A single test procedure to diagnose gestational diabetes mellitus. Acta Diabetol 2009;46(1):51-54

23 Maternal Health Division Ministry of Health \& Family Welfare Government of India. www.mohfw.gov.in \& www.nhm.gov.in. February 2018. Accessed June 28, 2021

24 Colagiuri S, Falavigna M, Agarwal MM, et al. Strategies for implementing the WHO diagnostic criteria and classification of hyperglycaemia first detected in pregnancy. Diabetes Res Clin Pract 2014;103(3):364-372
25 Hod M, Kapur A, Sacks DA, et al. The International Federation of Gynecology and Obstetrics (FIGO) initiative on gestational diabetes mellitus; a pragmatic guide for diagnosis, management and care. Int J Gynaecol Obstet 2015;131(Suppl3): S173-S211

26 Chittaranjan N. Purandare(FIGO), Shaukat Sadikot(IDF), Nam Cho Han(IDF) et al. FIGO-IDF Joint Statement and Declaration on Hyperglycemia in Pregnancy. IDF Congress. Abu Dhabi, 6th December 2017. www.diabetesatlas.org / atlas@idf.org. Accessed June 28, 2021

27 Bartha JL, Martinez-Del-Fresno P, Comino-Delgado R. Early diagnosis of gestational diabetes mellitus and prevention of diabetes-related complications. Eur J Obstet Gynecol Reprod Biol 2003;109(1):41-44

28 Li M, Hinkle SN, Grantz KL, et al. Glycaemic status during pregnancy and longitudinal measures of fetal growth in a multi-racial US population: a prospective cohort study. Lancet Diabetes Endocrinol 2020;8(4):292-300

29 Barker DJ, Thornburg KL. The obstetric origins of health for a lifetime. Clin Obstet Gynecol 2013;56(3):511-519

30 Combs CA, Gunderson E, Kitzmiller JL, Gavin LA, Main EK. Relationship of fetal macrosomia to maternal postprandial glucose control during pregnancy. Diabetes Care 1992;15(10):1251-1257

31 Jovanovic-Peterson L, Peterson CM, Reed GF, et al. Maternal postprandial glucose levels and infant birth weight: the diabetes in early pregnancy study. Am J Obstet Gynecol 1991;164(1 Pt 1) :103-111

32 Jovanovic L. Point: Oral hypoglycemic agents should not be used to treat diabetic pregnant women. Diabetes Care 2007;30(11):2976-2979

33 You and Your Hormones: An Education Resource for the Society of Endocrinology. https://www.yourhormones.info/ about. Accessed June 28, 2021

34 Savona-Ventura C, Chircop M. Birth weight influence on the subsequent development of gestational diabetes mellitus. Acta Diabetol 2003;40(2):101-104

35 Patrick M, Catalano. Fetal growth in normal and diabetic pregnancies. Textbook of Diabetes and pregnancy, Second edition, Publishers Informa Healthcare; 2008 Informa UK Ltd 